\title{
Editorial
}

\section{A sociologia \\ em seus distintos contextos}

\author{
Fabrício Monteiro Neves* \\ Joaze Bernardino-Costa** \\ \& Luís Augusto Sarmento Cavalcanti de Gusmão***
}

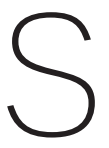

oa ainda muito controversa a alegação de que a sociologia, com seus diferentes contextos de estudo, seus distintos objetos, línguas, recursos, seja um empreendimento intelectual unificado. Como uma vez perguntou Michael Burawoy (2009, pág. 37):

Os sociólogos estão preparados para isso, ou estão muito divididos, sua comunidade é muito desigual, sua subsistência profissional é precária demais para buscar uma agenda? (Burawoy, 2009: 37).

Controvérsias à parte, neste número de Sociedade e Estado, embora não trazendo uma agenda global unificada da sociologia ao leitor, vê-se um mosaico complexo das distintas abordagens sociológicas que hoje se espalham pelo globo. Mais: esta agenda se apresenta aqui em suas facetas teóricas, empíricas e metodológicas.

A primeira parte do número é aberta com o dossiê organizado pelo professor do Departamento de Sociologia da Universidade de Brasília, Carlos Benedito Martins. Os textos são oriundos das conferências ocorridas por ocasião do XVIII Congresso Brasileiro de Sociologia, realizado em Brasília no mês de julho de 2017, que teve como temática principal a indagação, "Que sociologias fazemos? Interfaces com contextos local, nacional e global". Em seu texto introdutório ao dossiê, Martins articula os artigos selecionados para o presente volume com os objetivos do próprio evento:

Incentivar a reflexão a propósito da multiplicidade de configurações temáticas e teóricas que perpassam a produção sociológica contemporânea, realizada tanto no Brasil, quanto em outras partes do mundo (Martins, 2018: 335).

Gisèle Sapiro abre o Dossiê com o texto "Entre o nacional e o internacional: o surgimento histórico da sociologia como campo", propondo-se considerar a sociologia

\author{
* Fabrício Monteiro \\ Neves é professor \\ do Departamento \\ de Sociologia da \\ Universidade de \\ Brasília (UnB), \\ Brasília, Distrito \\ Federal, Brasil. \\ <fabriciomneves@ \\ gmail.com>. \\ ** Joaze Bernardino \\ Costa é professor \\ do Departamento \\ de Sociologia da \\ Universidade de \\ Brasília (UnB), \\ Brasília, Distrito \\ Federal, Brasil. \\ <joazebernardino@ \\ gmail.com>. \\ *** Luís Augusto \\ Sarmento Cavalcanti \\ de Gusmão é \\ professor do \\ Departamento \\ de Sociologia da \\ Universidade de \\ Brasília (UnB), \\ Brasília, Distrito \\ Federal, Brasil. \\ <gusma056@gmail. \\ com>.
}


em seu desenvolvimento histórico através de dois prismas: como disciplina e como campo. Segundo a autora, uma sociologia histórica da sociologia deveria lidar com o processo histórico de nacionalização da pesquisa e da capacitação, transcendendo sempre o nacionalismo metodológico. Para isso sugere repensar a sociologia histórica da sociologia, identificando quatro processos distintos: a institucionalização acadêmica, a profissionalização, a autonomização de um campo científico e a ascensão do mercado editorial. Finalmente, discute processos de nacionalização, internacionalização e transnacionalização.

Em seguida, Gerard Delanty nos oferece um instigante texto sobre os desafios à sociologia ocasionados pelas transformações históricas recentes que são enquadradas dentro do termo Antropoceno. No texto "Desafios da globalização e a imaginação cosmopolita: as implicações do Antropoceno", o autor reconhece que a noção de Antropoceno requer uma compreensão mais profunda da natureza espacial e temporal da sociedade humana, a qual não foi ofertada por meio dos estudos sobre globalização. A sociologia, segundo ele, ainda não digeriu completamente a chegada do Antropoceno, o qual requereria uma reinaugurada imaginação sociológica. A sociologia, nesta época de mudanças históricas, teria como tarefa específica oferecer maneiras pelas quais as pessoas pudessem ver suas vidas através do prisma do mundo social mais amplo e da história mundial.

O Antropoceno também é considerado no texto seguinte, de Rudolf Stichweh, sobre o conceito de "sociedade mundial". Em seu texto "Elementos-chave de uma teoria da sociedade mundial", o autor busca uma definição de sociedade - baseada na teoria dos sistemas sociais - para indicar um conceito de evolução sociocultural, culminando na formação da sociedade mundial moderna como sua configuração contemporânea. Define, então, os principais aspectos do sistema mundial em seu nexo com a diferenciação funcional de sistemas de função globalizados como a economia, a educação, a ciência e as instituições políticas. Por fim, o autor debruça-se sobre os mecanismos básicos da globalização: comunicação, migração, observação e conhecimento.

Volker Schmidt, em seu texto, prefere o termo "modernidade global". No artigo "Avanço e consequências da modernidade global", o autor assume que o termo em questão agrupa e sistematiza mudanças que foram observadas separadamente na literatura das ciências sociais, incluindo a literatura sobre globalização, a qual careceria de uma perspectiva integrativa. A discussão proposta com o termo modernidade global, segundo Schmidt, apresenta a mudança em sua complexidade, de forma multidimensional, inter-relacionada, levando em conta todas as esferas da vida. Sua conceituação está enraizada na distinção de Talcott Parsons entre o sistema social, 
o sistema cultural, o sistema de personalidade e organismo comportamental que, embora devassada, mostra-se útil heuristicamente.

O tema dos espaços globalizados é acionado no trabalho de Denise Jodelet, "Ciências sociais e representações: estudo dos fenômenos representativos e processos sociais, do local ao global". Teoricamente, a orientação é dada pela abordagem desenvolvida na psicologia social, a saber, o estudo das representações sociais, cuja pertinência é exposta para a compreensão do espaço globalizado. A autora ilustra sua posição com exemplos disseminados em trabalhos sobre os efeitos dos vetores da globalização sobre identidades sociais locais, e pelas posições adotadas pelos pesquisadores latino-americanos em face da importação de modelos emprestados dos círculos dominantes do Primeiro Mundo.

O tema da modernidade ainda se faz presente no dossiê com o texto "Os Estudos de etnometodologia de Garfinkel: uma investigação dos alicerces morais da vida pública moderna", de Anne Warfield Rawls. A autora argumenta ser Garfinkel incompreendido ainda hoje, principalmente em seus aspectos epistemológicos concernentes a objetos e práticas sociais. A consequência do argumento de Garfinkel, segundo Rawls, é que quaisquer desigualdades ou exclusões que impeçam as pessoas de cumprirem as condições de reciprocidade de uma interação - "condições de confiabilidade" - são uma ameaça à coerência, ao significado e à identidade da vida pública democrática moderna.

Se os artigos até agora trataram de discutir as tramas do local e do global, da sociedade moderna, mundial, os seguintes tratarão de temas mais circunscritos. É o caso do texto de Anthony Elliott, "A teoria do novo individualismo". Assume o autor que presenciamos atualmente as condições e consequências de um novo individualismo, globalizado, que se evidencia especialmente na economia "financeirizada" das indústrias de mídia e comunicação. Para o autor, o novo individualismo não se refere simplesmente a indivíduos ou a suas disposições psicológicas, ele se põe no próprio cerne do núcleo da cultura e da vida institucional. Assim, opera como um taquigrama para processos que moldam e que são moldados pelas transformações sociais globais.

Concomitante ao novo individualismo, presencia-se também novos arranjos comunitários, fortes e integradores. Em "Os novos atores jihadistas", Farhad Khosrokhavar nos mostra que, com a emergência do Estado Islâmico (EI), houve uma multiplicação de atores jihadistas, quantitativa e qualitativamente, principalmente na Europa, já atingindo novas faixas etárias. O texto nos oferece um perfil multifacetado desses novos atores que têm conseguido penetrar em instituições antes imu- 
nes à radicalização, como universidade, ensino médio, instituições governamentais, incluindo o exército e a polícia, adaptando-se cada vez mais à particularidade das sociedades-alvo.

Em seguida, no artigo de Sari Hanafi, "Pós-colonialismo versus pós-autoritarismo: o mundo árabe e a América Latina em uma perspectiva comparativa", é apresentada limitações nos usos das abordagens pós-coloniais nas ciências sociais, principalmente quando se tenta projetar tais estudos sobre o contexto árabe. Para que tais abordagens logrem avanços, deveriam ser complementadas por uma abordagem pós-autoritária, que poderia servir tanto ao mundo árabe quanto à América Latina.

Fecha o dossiê o texto "Sociologia e ciências sociais em tempos de austeridade", de Frédéric Lebaron, tratando de tema crucial em nosso tempo, as políticas de austeridade. O autor busca expandir o escopo da sociologia, contra o senso comum a sustentar que o tema da austeridade seja seara exclusiva da economia. A sociologia como disciplina científica é claramente competente para tornar o tema das "políticas de austeridade" objeto científico complexo, expandindo suas dimensões e seu universo semântico. Isso, segundo o autor, levaria a abordagem sociológica da austeridade a considerar dimensões como a crença econômica e seu discurso performativo.

Na seção de artigos avulsos continuamos com a discussão sobre o global e o local na sociologia. Daniel Bin nos oferece uma reflexão sobre a articulação sociológica de objetos teóricos globais e o estudo de fenômenos locais, visando abarcar uma realidade societária cada vez mais complexa. A hipótese do autor, no artigo "O global e o local na pesquisa sociológica", é que, por mais que a realidade nos seja mais imediatamente apreensível ao nível local das relações, são nas macroforças que encontramos a explicação dessa mesma realidade.

Em seguida, Bráulio Alves da Silva, Antônio Augusto Prates, Alexandre Cardoso e Nina Rosas de Castro, no texto "O suicídio no Brasil contemporâneo", visam completar uma lacuna nos estudos sociológicos no Brasil: o estudo do suicídio. Os autores apresentam os padrões das mortes por suicídios no Brasil entre os anos de 1980 a 2010, usando informações do Ministério da Saúde. Ao replicarem o estudo clássico de Durkheim, buscam apresentar o efeito de elementos de integração social sobre as taxas de suicídios e a importância do espaço para o estudo desse fenômeno. Os resultados apontam uma possível associação entre fatores de baixa integração social e expansão da taxa de suicídio no Brasil.

Finalmente, fechamos a seção de artigos com o texto "Cidadania em espaços (sub) urbanos: o Teatro do Oprimido no Alto da Cova da Moura e no Vale da Amoreira", de 
André Carmo. O autor estudou as atividades de dois grupos comunitários do Teatro do Oprimido - DRK (Alto da Cova da Moura, Amadora) e ValArt (Vale da Amoreira, Moita), procurando compreender como pode a cidadania através da arte contribuir para a construção de cidades mais justas, e quais os desafios e limites que este processo enfrenta. Carmo nos mostra que é através do teatro - sobretudo pela revelação e valorização das experiências, histórias e narrativas pessoais e contextuais -, no âmbito da sua intervenção social e política, que se combatem alguns dos efeitos trágicos da urbanização contemporânea e que se diluem as fronteiras que separam estes bairros do seu entorno.

Como de praxe, a edição é finalizada com resenhas. A primeira, Como os países ricos ficaram ricos ... e por que os países pobres continuam pobres, livro de Erik S. Reinert, publicado em 2016, é de autoria de Jorgemar Felix. A segunda, escrita por Gustavo Margarites e Gabriella de Freitas, versa sobre o livro de Neil Fligstein e Doug Mcadam, A theory of fields, publicado em 2012.

Obs. Na edição publicada no site da revista (http://periodicos.unb.br/index.php/ estado/index) há ainda a tradicional seção de resumos das teses e dissertações defendidas no Programa de Pós-Graduação em Sociologia da Universidade de Brasília (PGSOL).

Boa leitura!

\section{Referências}

BURAWOY, Michael. Challenges for a global sociology. Contexts, v. 8, n. 4, p. 36-41, 2009.

MARTINS, Carlos Benedito. A sociologia e suas interfaces com contextos local, nacional e global. Sociedade e Estado, v. 33, n. 2, p. 335-348, Maio-Ago. 2018. 